NIST Handbook 150-5

\title{
NVLAP \\ Construction \\ Materials \\ Testing
}

Thomas Hettenhouser

Timothy Rasinski

This publication is available free of charge from:

https://doi.org/10.6028/NIST.HB.150-5-2020

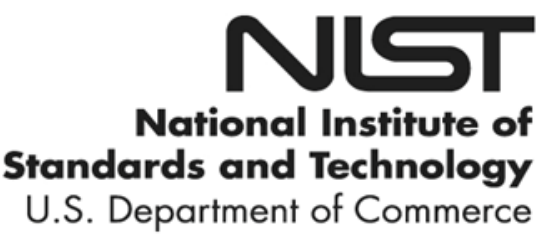




\section{This page is intentionally left blank.}


NIST Handbook 150-5

\title{
NVLAP \\ Construction \\ Materials \\ Testing
}

\author{
Thomas Hettenhouser \\ Timothy Rasinski \\ National Voluntary Laboratory Accreditation Program \\ Standards Coordination Office \\ Laboratory Programs
}

This publication is available free of charge from:

https://doi.org/10.6028/NIST.HB.150-5-2020

May 2020

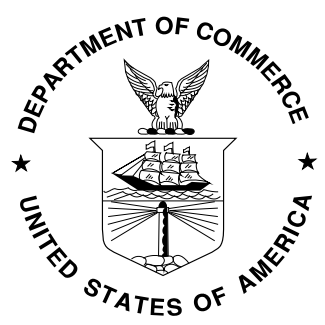

U.S. Department of Commerce Wilbur L. Ross, Jr., Secretary

National Institute of Standards and Technology Walter Copan, NIST Director and Undersecretary of Commerce for Standards and Technology 
Certain commercial entities, equipment, or materials may be identified in this document in order to describe an experimental procedure or concept adequately. Such identification is not intended to imply recommendation or endorsement by the National Institute of Standards and Technology, nor is it intended to imply that the entities, materials, or equipment are necessarily the best available for the purpose.

National Institute of Standards and Technology Handbook 150-5-2020

Natl. Inst. Stand. Technol. Handbook 150-5-2020, 17 pages (May 2020)

This publication is available free of charge from: https://doi.org/10.6028/NIST.HB.150-5-2020 


\section{NVLAP AND THE NVLAP LOGO}

The term NVLAP and the NVLAP logo are federally registered certification marks of the National Institute of Standards and Technology and the federal government, who retain exclusive rights to control the use thereof. Permission to use the term and/or logo is granted to NVLAP-accredited laboratories for the limited purposes of announcing their accredited status, and for use on reports that describe only testing and calibration within the scope of accreditation. NIST reserves the right to control the quality of the use of the term NVLAP and of the NVLAP logo. 


\section{Contents}

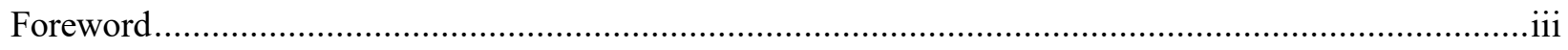

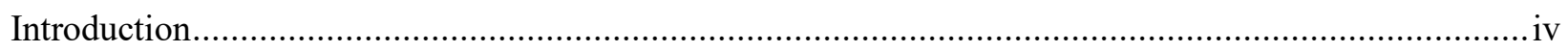

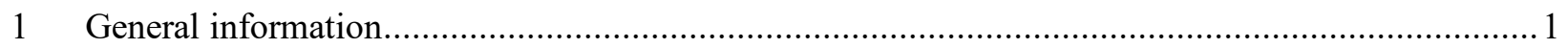

$1.1 \quad$ Scope

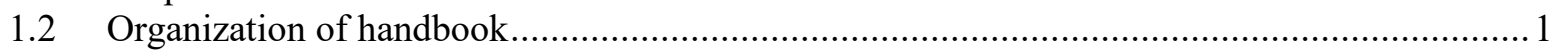

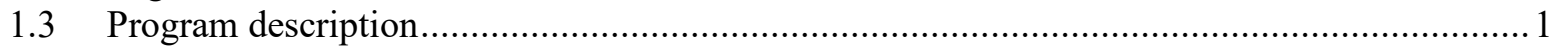

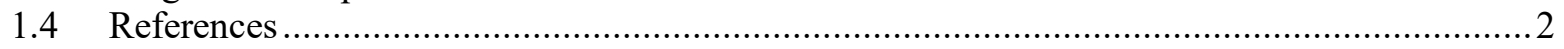

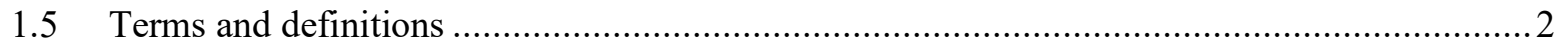

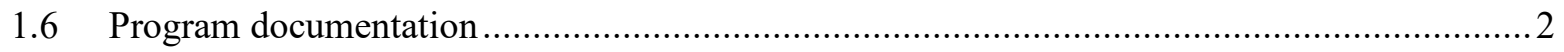

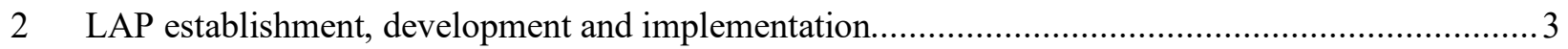

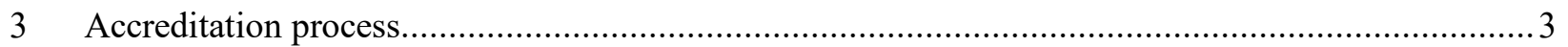

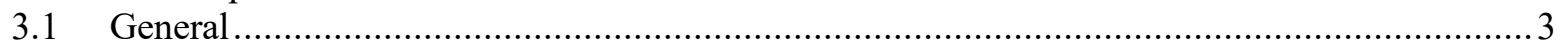

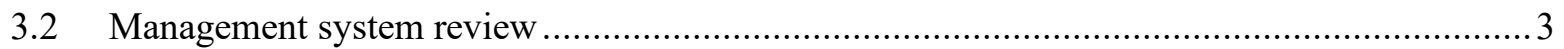

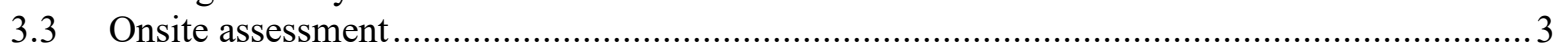

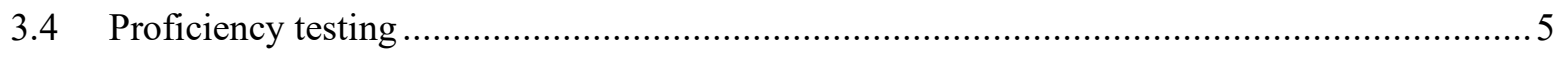

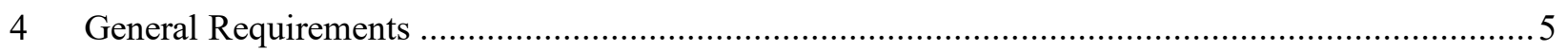

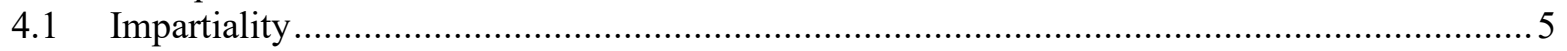

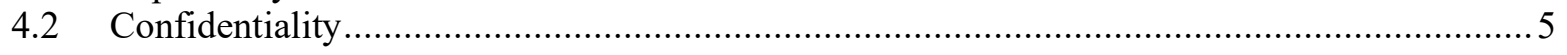

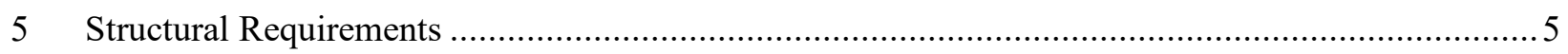

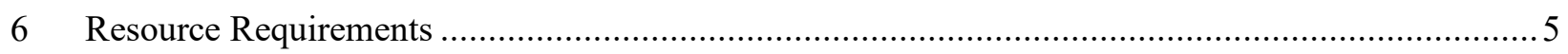

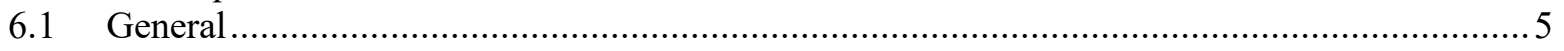

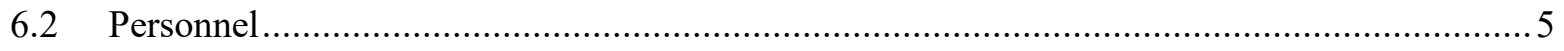

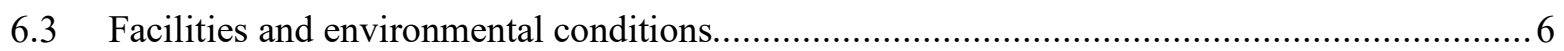

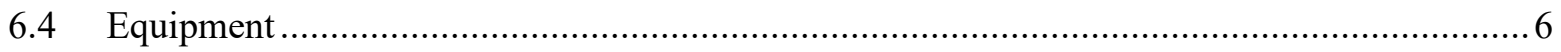

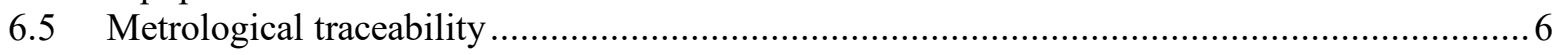

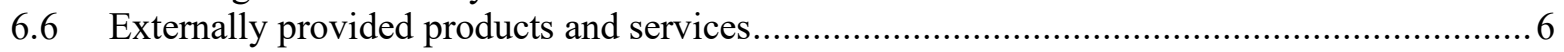

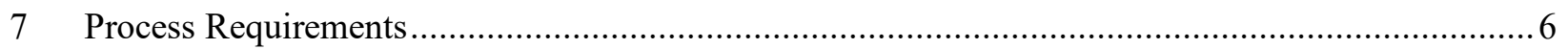

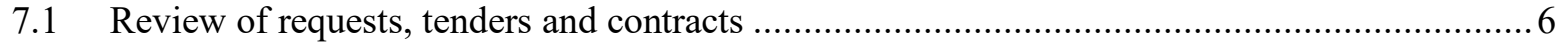

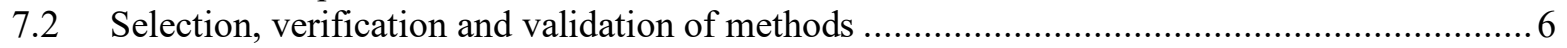

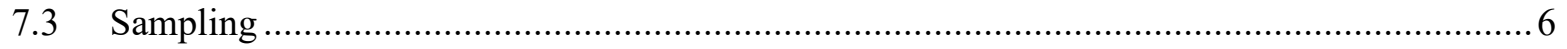

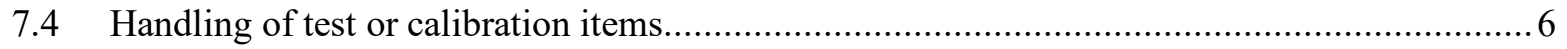

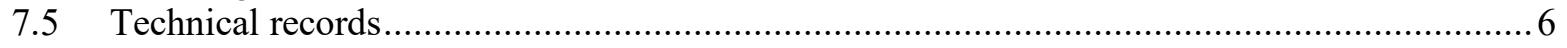

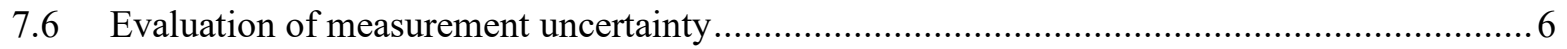

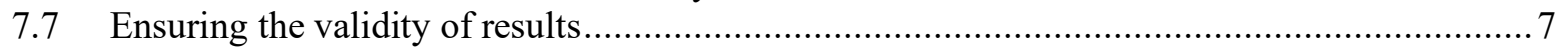

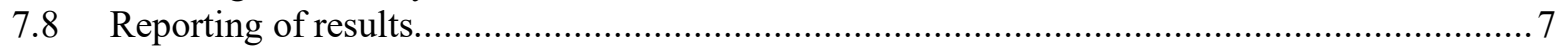

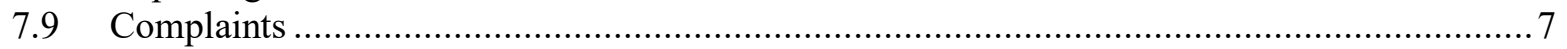

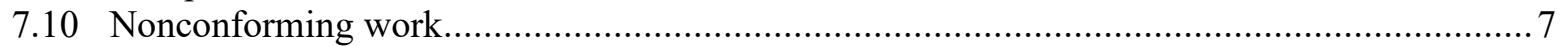

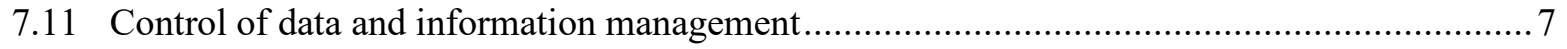




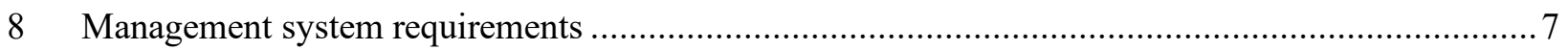

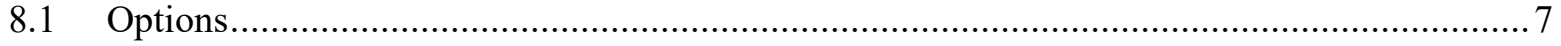

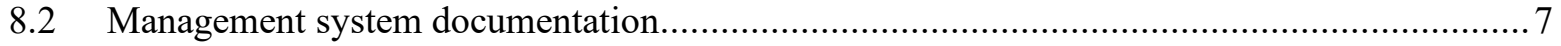

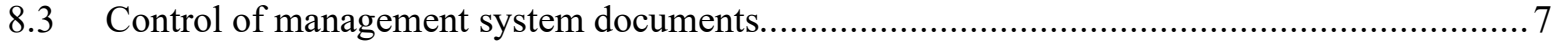

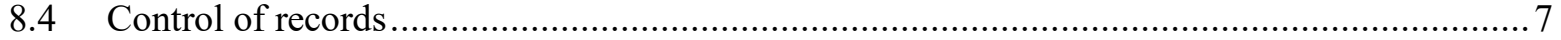

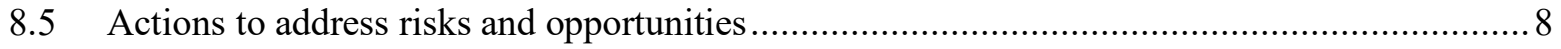

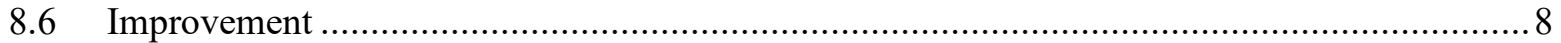

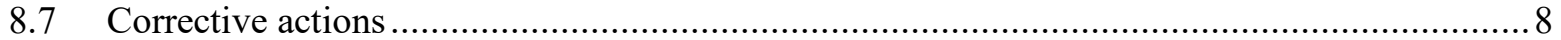

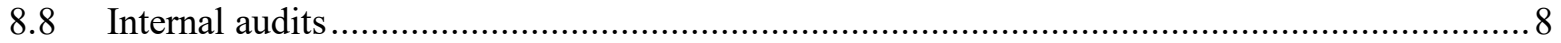

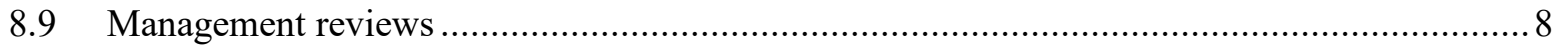




\section{Foreword}

The NIST Handbook 150 publication series sets forth the procedures, requirements, and guidance for the accreditation of testing and calibration laboratories by the National Voluntary Laboratory Accreditation Program (NVLAP). The series is comprised of the following publications:

- NIST Handbook 150, NVLAP Procedures and General Requirements, which contains the general procedures and requirements under which NVLAP operates as an unbiased third-party accreditation body; and

- NIST Handbook 150-xx program-specific handbooks, which supplement NIST Handbook 150 by providing additional requirements, guidance, and interpretive information applicable to specific NVLAP laboratory accreditation programs (LAPs).

The program-specific handbooks are not stand-alone documents, but rather are companion documents to NIST Handbook 150 and the referenced ISO/IEC 17025 requirements. They tailor the general criteria found referenced in NIST Handbook 150 to the specific tests, calibrations, or types of tests or calibrations covered by a LAP.

NIST Handbook 150-5, Construction Materials Testing, presents the technical requirements and guidance for the accreditation of laboratories under the Construction Materials Testing (CMT) LAP. The 2020 edition incorporates changes resulting from the release of the 2017 edition of ISO/IEC 17025, General requirements for the competence of testing and calibration laboratories, and NIST Handbook 150, as well as editorial improvements. The 2020 edition of NIST Handbook 150-5 supersedes and replaces the 2005 edition.

The handbook was revised with the participation of technical experts in the field of construction materials testing and was approved by NVLAP. The following main changes have been made to this handbook with respect to the previous edition:

- all references to applicable international guides and standards have been updated;

- the numbering has been updated to reflect that used by ISO/IEC 17025:2017, General requirements for the competence of testing and calibration laboratories (hereafter referred to as ISO/IC 17025);

- redundant requirements for specific equipment, records, etc., found in the various standards for test methods used in the program were removed.

This handbook is also available on the NVLAP web site (https://www.nist.gov/nvlap).

Questions or comments concerning this handbook should be submitted to NVLAP, National Institute of Standards and Technology, 100 Bureau Drive, Stop 2140, Gaithersburg, MD, 20899-2140; phone: 301-975-4016; fax: 301-926-2884; e-mail: nvlap@nist.gov. 


\section{Introduction}

The Construction Materials Testing laboratory accreditation program (LAP) began in 1978 as the Concrete LAP. The program gradually expanded beyond concrete testing to include other testing areas such as admixtures, aggregates, cement, geotextiles, road and paving materials, soil and rock, and steel materials.

NVLAP accreditation is based on the evaluation of a laboratory's technical qualifications and competence for conducting specific standard test methods in construction materials testing. Test methods that relate to this program may be developed by a trade, professional, governmental, or standards-writing organization.

Accreditation is available to any laboratory (including commercial, manufacturer, university, and federal, state, and local government laboratories) that tests in accordance with standard construction materials test methods. A foreign-based laboratory may also be accredited by NVLAP if the laboratory meets the same requirements as domestic laboratories and pays any required additional fees associated with conducting the onsite assessment.

To be granted accreditation, a laboratory shall satisfy the NVLAP requirements contained in NIST Handbook 150, this handbook, and test methods on the (proposed) scope of accreditation. 


\section{General information}

\subsection{Scope}

1.1.1 NIST Handbook 150-5 specifies technical requirements and provides guidance for NVLAP accreditation of laboratories that provide construction materials testing. It supplements NVLAP general requirements found in ISO/IEC 17025 by tailoring the general criteria found in ISO/IEC 17025 to the specific tests and types of tests covered by the CMT LAP.

1.1.2 ISO/IEC 17025, NIST Handbook 150, this handbook, and test methods indicated on the (proposed) scope of accreditation constitute the collective body of requirements that must be met by a laboratory seeking NVLAP accreditation for the CMT LAP.

1.1.3 This handbook is intended for information and use by accredited construction materials testing laboratories, assessors conducting onsite assessments, laboratories seeking accreditation, other laboratory accreditation systems, users of laboratory services, and others needing information on the requirements for NVLAP accreditation under the CMT LAP.

\subsection{Organization of handbook}

The numbering and titles of this handbook match those of ISO/IEC 17025. The primary subclauses in clauses 4 through 8 (e.g., 4.1, 4.2, etc.) are also numbered and titled to correspond with those of ISO/IEC 17025, even when there are no requirements additional to those in ISO/IEC 17025.

\subsection{Program description}

1.3.1 This accreditation program is designed to satisfy the requirements of contractors, state and local governments, and federal agencies specifying accreditation for construction materials testing laboratories.

1.3.2 Accreditation is available for standard test methods in the areas of admixtures, aggregates, cement, concrete, geotextiles, road and paving materials, soil and rock, steel materials and other areas as deemed necessary.

1.3.3 A listing of the test methods included in the program is given in the test methods and calibration parameter listing available on the NVLAP website. The list is grouped by the program "product testing," then by "construction materials." Once at the construction materials program level, the tests are grouped by:

- admixtures;

- aggregates;

- cement;

- concrete;

- geotextiles;

- road and paving materials;

- $\quad$ soil and rock;

- $\quad$ standard practices and specifications; 
- $\quad$ steel materials; and

- fireproofing.

\subsection{References}

The following documents are referenced in this handbook. For dated references, only the edition cited applies. For undated references, the latest edition of the referenced document (including any amendments) shall apply within one year of publication or within another time limit specified by regulations or other requirement documents.

— NIST Handbook 150, NVLAP Procedures and General Requirements

— ISO/IEC 17025, General requirements for the competence of testing and calibration laboratories

- IEEE Standard 1012, IEEE Standard for Software Verification and Validation

- ASTM C125, Standard Terminology Relating to Concrete and Concrete Aggregates

- ASTM C219, Standard Terminology Relating to Hydraulic Cement

\section{$1.5 \quad$ Terms and definitions}

For the purposes of this handbook, the terms and definitions given in NIST Handbook 150, ASTM C125 and ASTM C219, and the standards for which the laboratory seeks accreditation apply.

\subsection{Program documentation}

\subsubsection{General}

Assessors use NVLAP checklists and test method review summary forms to ensure assessment consistency. Checklists assist assessors in documenting compliance with the NVLAP requirements found in NIST Handbook 150, ISO/IEC 17025, this handbook, and the specific test methods for which accreditation is requested. Checklists and test method review summary forms are part of the Onsite Assessment Report (see NIST Handbook 150). These documents are available on the NVLAP website.

\subsubsection{NVLAP General Criteria Checklist}

All NVLAP programs use the NVLAP General Criteria Checklist (ISO/IEC 17025) (formerly called the NIST Handbook 150 Checklist), which contains the requirements published in ISO/IEC 17025 and NIST Handbook 150. The checklist items are numbered to correspond to clauses 4 through 8 of ISO/IEC 17025 and annexes A, B, and E of NIST Handbook 150.

\subsubsection{NIST Handbook 150-5 Checklist}

The NIST Handbook 150-5 Checklist (also referred to as the CMT Program-Specific Checklist) addresses the requirements specific to construction materials testing given in NIST Handbook 150-5. 


\subsubsection{Test Method Review Summary}

Because of the very large number of relevant standards and test methods in the CMT LAP, the assessor uses Test Method Review Summary forms, along with applicable checklists, to evaluate the laboratory's compliance to the test methods. The evaluation of the test methods by the assessor ranges from observing tests to having laboratory staff describe the test procedures. The assessor notes on the Test Method Review Summary document the depth into which each part of the test method was reviewed (observed test, examined apparatus, walked/talked through test, listened to description of procedures).

\subsubsection{NVLAP lab bulletins}

NVLAP lab bulletins are issued to laboratories and assessors, when needed, to clarify program-specific requirements and to provide information about the most current program additions and changes. Lab bulletins providing additions or changes to the current program will supersede the requirements of the current published handbook until the additions or changes are published in a revision of the handbook. Lab bulletins are posted on the program-specific handbooks page of the NVLAP website.

\section{LAP establishment, development and implementation}

This clause contains no information additional to that provided in NIST Handbook 150, clause 2.

\section{$3 \quad$ Accreditation process}

\subsection{General}

An overview of the laboratory accreditation process is provided in NIST Handbook 150, clause 3, and includes information pertaining to application for accreditation; onsite assessment; proficiency testing; accreditation decision; granting accreditation; renewal of accreditation; changes to scope of accreditation; monitoring visits; and suspension, denial, revocation, and voluntary termination of accreditation.

\subsection{Management system review}

Prior to the onsite assessment, the assigned assessor will review all relevant management system documentation against NVLAP requirements, including the requirements of this handbook, NIST Handbook 150, and ISO/IEC 17025. During this review, the assessor may request additional management system documents and/or records, which will be returned upon request.

\subsection{Onsite assessment}

\subsubsection{General information}

3.3.1.1 The purpose of the onsite assessment is to determine the laboratory's compliance with ISO/IEC 17025, NIST Handbook 150, this handbook, and its own management system and to assess the capability and competence of the testing activities for which accreditation is being requested.

3.3.1.2 Testing performed at locations other than the primary facility covered under the accreditation will be reviewed on a case-by-case basis to determine the extent of onsite review necessary. 
3.3.1.3 Prior to the onsite assessment, the NVLAP assessor will provide a preliminary agenda. The laboratory may not be granted accreditation or accreditations renewed for any test method where it is not prepared to conduct test demonstrations, does not have equipment in good working order, and/or is not ready for examination according to the requirements identified in ISO/IEC 17025, this handbook, and NIST Handbook 150.

3.3.1.4 In addition to the checklists, to help assure the completeness, objectivity, and uniformity of the onsite assessment, the assessor uses the NVLAP Test Method Review Summary form to review the capability of laboratory personnel to perform testing for which accreditation is sought. The test method review ranges from observing tests to having laboratory staff describe the test procedures. The assessor notes the depth to which each part of the test method was reviewed and records the results of the review.

\subsubsection{Typical onsite assessment}

The NVLAP assessor performs the following activities during a typical onsite assessment:

a) Conducts an opening meeting with the laboratory to explain the purpose of the onsite visit and to discuss the schedule for the day(s). At the discretion of the laboratory manager, other staff may attend the meeting.

b) Reviews laboratory documentation not provided for review prior to the assessment, including the management system, equipment and maintenance records, record-keeping procedures, testing procedures, laboratory test records and reports, personnel competency records, personnel training plans and records, and safeguards for the protection of sensitive and proprietary information.

At least one laboratory staff member shall be available to answer questions; however, the assessor may request to review the documents and records alone.

c) Examines equipment and facilities, observes demonstration of selected procedures by the appropriate personnel assigned to conduct the tests, and interviews those personnel. The demonstrations requested may be selective or all-inclusive and shall include use of test devices, preparation of test device, establishment of test conditions, and setup/use of major equipment. The assessor will also review the test data and examine the hardware/software for functionality and appropriateness.

d) Completes an Onsite Assessment Report, which contains the NVLAP Onsite Assessment Signature Sheet with Narrative Summary, NVLAP General Criteria Checklist (ISO/IEC 17025), NIST Handbook 150-5 Checklist, and the Test Method Review Summary. The assessor will also enter any nonconformities and/or comments into the NVLAP interactive website (NIWS).

e) Conducts a closing meeting with the laboratory to explain the findings of the visit. At the closing meeting, the report shall be signed by the assessor and the laboratory's authorized representative to acknowledge the discussion of the outcome of the onsite assessment. The authorized representative's signature does not necessarily indicate agreement, merely receipt, and challenges may be made through NVLAP. The process for resolving nonconformities identified during the onsite is documented in NIST Handbook 150. 


\subsection{Proficiency testing}

3.4.1 Proficiency testing is conducted by a proficiency testing (PT) provider that is acceptable to NVLAP. Please refer to the program specific web page or contact your program manager for information.

3.4.2 The proficiency testing results will be monitored by NVLAP. The laboratory's accreditation may be suspended if the proficiency testing results indicate unsatisfactory performance for two consecutive rounds of proficiency samples.

\section{$4 \quad$ General Requirements}

\subsection{Impartiality}

There are no requirements additional to those set forth in ISO/IEC 17025.

\subsection{Confidentiality}

There are no requirements additional to those set forth in ISO/IEC 17025.

\section{$5 \quad$ Structural Requirements}

There are no requirements additional to those set forth in ISO/IEC 17025.

\section{Resource Requirements}

\subsection{General}

There are no requirements additional to those set forth in ISO/IEC 17025.

\subsection{Personnel}

6.2.1 If the standard practice(s) for which the laboratory desires accreditation specifies that the laboratory operate under the technical direction of a full-time professional engineer (PE), the laboratory shall have a full time PE.

6.2.2 For each staff member, the staff member's immediate supervisor, or a designee appointed by the laboratory director, shall conduct annually an assessment and an observation of performance. These annual performance reviews shall be documented, dated, signed by the supervisor and the employee, retained in the personnel file, and be available for review by the assessor. 


\subsection{Facilities and environmental conditions}

There are no requirements additional to those set forth in ISO/IEC 17025.

\subsection{Equipment}

There are no requirements additional to those set forth in ISO/IEC 17025.

\subsection{Metrological traceability}

There are no requirements additional to those set forth in ISO/IEC 17025.

\subsection{Externally provided products and services}

There are no requirements additional to those set forth in ISO/IEC 17025.

\section{$7 \quad$ Process Requirements}

\subsection{Review of requests, tenders and contracts}

There are no requirements additional to those set forth in ISO/IEC 17025.

\subsection{Selection, verification and validation of methods}

There are no requirements additional to those set forth in ISO/IEC 17025.

\subsection{Sampling}

All requirements of ISO/IEC 17025 for sampling apply to subsampling. When a laboratory tests some subset of the test item(s) supplied by the customer, it is subsampling.

\subsection{Handling of test or calibration items}

There are no requirements additional to those set forth in ISO/IEC 17025.

\subsection{Technical records}

There are no requirements additional to those set forth in ISO/IEC 17025.

\subsection{Evaluation of measurement uncertainty}

There are no requirements additional to those set forth in ISO/IEC 17025. 


\subsection{Ensuring the validity of results}

7.7.1 The laboratory's procedure for monitoring the validity of results shall apply to each test method on the scope of accreditation and address the requirements in sections 7.7.1 and 7.7.3 of ISO/IEC 17025.

7.7.2 The laboratory shall participate in PT as described in section 3.4.1.

\subsection{Reporting of results}

There are no requirements additional to those set forth in ISO/IEC 17025.

\subsection{Complaints}

There are no requirements additional to those set forth in ISO/IEC 17025.

\subsection{Nonconforming work}

There are no requirements additional to those set forth in ISO/IEC 17025.

\subsection{Control of data and information management}

There are no requirements additional to those set forth in ISO/IEC 17025.

\section{Management system requirements}

\subsection{Options}

There are no requirements additional to those set forth in ISO/IEC 17025.

\subsection{Management system documentation}

There are no requirements additional to those set forth in ISO/IEC 17025.

\subsection{Control of management system documents}

There are no requirements additional to those set forth in ISO/IEC 17025.

\subsection{Control of records}

All records related to the scope of accreditation will be held for 3 years. 


\subsection{Actions to address risks and opportunities}

There are no requirements additional to those set forth in ISO/IEC 17025.

\subsection{Improvement}

There are no requirements additional to those set forth in ISO/IEC 17025.

\subsection{Corrective actions}

There are no requirements additional to those set forth in ISO/IEC 17025.

\subsection{Internal audits}

An applicant laboratory shall conduct at least one complete internal audit prior to the first onsite assessment.

\subsection{Management reviews}

An applicant laboratory shall perform at least one complete management review prior to the first onsite assessment. 